\title{
Candida glabrata: a review of its features and resistance
}

\author{
C. F. Rodrigues $\cdot$ S. Silva $\cdot$ M. Henriques
}

Received: 16 September 2013 / Accepted: 22 October 2013 / Published online: 19 November 2013

(C) Springer-Verlag Berlin Heidelberg 2013

\begin{abstract}
Candida species belong to the normal microbiota of the oral cavity and gastrointestinal and vaginal tracts, and are responsible for several clinical manifestations, from $\mathrm{mu}-$ cocutaneous overgrowth to bloodstream infections. Once believed to be non-pathogenic, Candida glabrata was rapidly blamable for many human diseases. Year after year, these pathological circumstances are more recurrent and problematic to treat, especially when patients reveal any level of immunosuppression. These difficulties arise from the capacity of $C$. glabrata to form biofilms and also from its high resistance to traditional antifungal therapies. Thus, this review intends to present an excerpt of the biology, epidemiology, and pathology of $C$. glabrata, and detail an approach to its resistance mechanisms based on studies carried out up to the present.
\end{abstract}

\section{Introduction}

The incidence of fungal infections has increased significantly in the last several decades, contributing to high levels of morbidity and mortality [1]. This fact is mainly due to the rise in antimicrobial resistance and the limited number of efficient antifungal drugs, which still have many side effects. Of the fungi considered as human pathogens, some members of the genus Candida are the most commonly recovered from fungal infections [2]. The use of broad-spectrum antibiotics, catheters and parenteral nutrition, the presence of immunosuppression, the disruption of mucosal barriers, and the use of chemotherapy and radiotherapy are among the most significant predisposing factors for invasive fungal infections development [3]. The Candida genus comprises over 150 heterogeneous

C. F. Rodrigues $\cdot$ S. Silva $\cdot$ M. Henriques $(\triangle)$

IBB - Institute for Biotechnology and Bioengineering, Centre of

Biological Engineering, University of Minho, 4710-057 Braga,

Portugal

e-mail: mcrh@deb.uminho.pt species [4], but only a minority are associated to human candidosis, since roughly $65 \%$ of Candida species are unable to grow at a temperature of $37^{\circ} \mathrm{C}$, enabling them to prosper as pathogens or commensals of humans [4]. The genus is composed of a heterogeneous group of organisms, and more than 17 different Candida species are known to be etiological agents of human infections; however, more than $90 \%$ of invasive infections are due to Candida species [5]. The pathogenicity of Candida species is attributed to certain virulence factors, such as the ability to evade host defenses, adhesion and biofilm formation (on host tissue or on medical devices), and the production of tissue-damaging hydrolytic enzymes such as proteases, phospholipases, and hemolysins [2].

Of the Candida species isolated from humans, Candida albicans is the most prevalent in both health and disease conditions. However, whilst mycological studies have been shown that C. albicans represents over $80 \%$ of isolates, in the last two decades, the number of infections due to non-Candida albicans Candida (NCAC) species has increased significantly, namely due to Candida glabrata. In fact, recent studies suggested that fungemia has been associated with NCAC species [6-9] and the incidence of $C$. glabrata is higher in adults than in children, and is lower in neonates $[10,11]$. This species lacks a number of the virulence factors allied to other Candida pathogenicity, such as hyphal growth or the ability to secrete proteases [12]. Despite that, C. glabrata is a growing concern in clinical settings, where it causes mucosal infections and is related to around $15 \%$ of all Candida-related systemic bloodstream infections [13-19].

Candida epidemiology has shown that humans are exposed recurrently to Candida in food and other sources. Vazquez and colleagues [20] revealed that patients with a new acquisition of $C$. glabrata had extended hospitalization and repeated prior antimicrobial use compared to patients with no Candida exposition. Moreover, differently from $C$. albicans, former studies [21,22] indicated that $75 \%$ of patients generally carried the same strain type of $C$. glabrata 
over time [20], with minimal strain diversity among individual patients.

Candida infection is the third most common cause of nosocomial infections in patients requiring intensive care and the most common etiologic agent of fungal-related biofilm infections. Biofilms are biological communities with an extraordinary degree of organization, in which micro-organisms form structured, coordinated, and functional communities, embedded in a self-created extracellular matrix. Biofilm production is also associated with a high level of antimicrobial resistance of the associated organisms. The ability of Candida species to form drug-resistant biofilms is an important factor in their contribution to human disease, but it is also recognized that the more general provision of new medical practices (immunosuppressive therapy, invasive surgical procedures, and the use of broadspectrum antibiotics) are highly significant as well [23-25]. In the widely held view of microbial biofilms [26], sessile cells within biofilms are less susceptible to antimicrobial agents than planktonic cells [27], since the development of drug resistance has been linked with an increase in the maturation process.

Antifungal drugs are active by either killing the fungal cells, e.g., affecting a substance in the cell wall, causing a leak out of the cell contents and death, or by preventing fungal cells from growing and reproducing. There are many antifungal classes: polyenes, which includes amphotericin, nystatin, and pimaricin; azoles, including fluconazole, itraconazole, ketoconazole, miconazole, voriconazole, posaconazole, and rosaconazole; echinocandins, such as caspofungin and micafungin; and allylamines, including naftifine, terbinafine, morpholine drug, amorolfine, and griseofulvin; and the antimetabolite antifungal drugs, in which 5-fluorocytosine is incorporated.

Amphotericin B and fluconazole are among the antifungal agents most widely used to treat systemic fungal infections. The former has its use limited due to its high degree of toxicity in humans. The latter is frequently prescribed to treat Candida infections due to its excellent patient tolerance and minimal side effects, although a great number of species of Candida display fluconazole resistance. The growing worldwide use of this drug to treat candidemia is one of the principal causes of the recent increase in the prevalence of NCAC species [28]. Concerning that information and despite significant research aimed at identifying virulence factors of $C$. glabrata $[2,4,15]$, little is known about the mechanism of its resistance to antifungal agents. Thus, in this review, we aim to provide an overview of the $C$. glabrata resistance factors, as well as the biology and virulence factors of $C$. glabrata .

\section{Physiological and biochemical characterization of Candida glabrata}

Originally, C. glabrata was classified in the Torulopsis genus due to its lack of pseudohyphae. In fact, in 1978, this species was shown to have no polymorphic growing, being only grown as blastoconidia. It was then considered that the ability to form pseudohyphae was not a trustworthy distinctive aspect for members of the genus Candida and it was suggested that Torulopsis glabrata might be classified in the genus Candida, for its human pathogenicity [29]. On Sabouraud Dextrose Agar (SDA), C. glabrata forms shining, smooth, and creamcolored colonies, which are fairly indistinguishable from those of other Candida species, except for their relative size, which can be rather small. Candida glabrata cells $(1-4 \mu \mathrm{m})$ are remarkably smaller than C. albicans $(4-6 \mu \mathrm{m})$, Candida tropicalis $(4-8 \mu \mathrm{m})$, and Candida parapsilosis $(2.5-4 \mu \mathrm{m})$ blastoconidia [4]. Regarding the chromogenic medium, CHROMagar ${ }^{\mathrm{TM}}$ Candida (CHROMagar, Paris, France), $C$. glabrata colonies appear white, pink to purple, and concerning the biochemical reactions, it ferments and assimilates only glucose and trehalose. Finally, in relation to its genetic features, $C$. glabrata has a critical distinction due to its haploid genome, in contrast to the diploid genome of $C$. albicans and several other NCAC species [29]. A summarized list of features is presented on Table 1 .

The genome of $C$. glabrata (CBS138/American Type Culture Collection, ATCC2001) was sequenced [29, 30], showing that this species shares a common ancestor with Saccharomyces cerevisiae [31]. Thus, the first has lost many more genes than S. cerevisiae, decreasing traces of duplication to a minimum and leading to the complete loss of some metabolic pathways [29, 30]. Even though it has reserved homology with the S. cerevisiae genes of the mating pathway [32], $C$. glabrata is haploid and, indeed, several deficiencies in the mating pathway have been also identified [33, 34].

Moreover $C$. glabrata has lost various genes, such as the gene needed for galactose (GAL1, GAL7, GAL10), phosphate (PHO3, PHO5, PHO11, PHO12), nitrogen (DAL1, DAL2), sulfur metabolism (SAM4), and pyridoxine biosynthesis (SNO1, SNO2, SNO3) [12, 35]. The natural auxotrophy of $C$. glabrata, such as the inability to synthesize nicotinic acid, pyridoxine, and thiamine [7], and the inability to use galactose or engineered amino acid auxotrophy $[35,36]$, is generally compensated by the mammalian host environment. Additionally, expansion of genes involved in cell wall organization occurred in C. glabrata, possibly facilitating adherence to a broad spectrum of surfaces. It is important to emphasize that the gain and loss of these relevant genes may be crucial for a functional differentiation between species and could be related to $C$. glabrata's adaptation as a mammalian commensal $[12,33-36]$.

Nutrient limitation, oxidative response, competition with other microorganisms, causative agents as protective mechanisms, and the impossibility to generate resistant spores are stress causes (intrinsic or habitat sourced) to C. glabrata [37]. Hence, somatic cells require holding viability on surfaces outside the host, demanding a high stress tolerance. Matched to other Candida species, C. glabrata appears to be one of the 
Table 1 Characterization of Candida glabrata general features $[12,29,30]$

\begin{tabular}{ll}
\hline Feature & Candida glabrata characteristics \\
\hline Ploidy & Haploid \\
Hyphae/pseudohyphae & Absent \\
Colonies on SDA & Very small/cream-color \\
Cell size & $1-4 \mu \mathrm{m}$ \\
Growth on CHROMagarTM & White, pink/purple \\
Biochemical reactions & Ferments and assimilates glucose \\
& and trehalose \\
Virulence & Opportunistic pathogen \\
Major sites of infection & Vaginal, oral, disseminated \\
Biofilm formation & Yes \\
Major adhesins & Lectins \\
Mating genes & Present \\
Sexual cycle & Unknown \\
Clonal population structure & Yes \\
Phenotypic switching & Present \\
Auxotrophy & Niacin, thiamine, pyridoxine \\
Mitochondrial function & Petite-positive \\
Epidemiology of infection & Principally nosocomial (except vaginal) (frequently mixed fungal infection) \\
& Immunocompromised or debilitated host \\
& Specific risk factors: prolonged hospitalization, prior antibiotic use, \\
& use of fluconazole, patient exposure, hand carriage by hospital personnel \\
\hline
\end{tabular}

more robust, being able to survive on inanimate surfaces for more than 5 months, while the viability of $C$. albicans is limited to 4 months and $C$. parapsilosis cells die after 2 weeks $[37,38]$.

\section{Candida glabrata-host interactions}

Candida glabrata cells are able to colonize commensally the mouth, esophagus, intestines, and vagina mucosal surfaces, but very little is known about its interaction with the host and defense mechanisms. It is expected that host mechanisms control C. glabrata, suppressing the expression of its pathogenic properties, and, in this manner, preventing infection [37, 38].

Phagocytic cells (neutrophils, dendritic cells, and macrophages) constitute the primary response of the innate host immune system against Candida infections. After internalization of the fungal pathogen, formation of the phagolysosome continues inside the phagocytic cells, for the destruction of the overwhelmed microorganism. The organelle harbors a damaging and highly toxic internal phagolysosome for the elimination, including low $\mathrm{pH}$, hydrolytic enzymes, potent reactive oxygen and nitrogen species (DNA damage), proteins, and lipids of the pathogen. Trapped microorganisms have developed diverse strategies to survive the oxidative burst and to escape from the phagolysosome, including many antioxidant defense enzymes (catalase, reductase, superoxide dismutase, thioredoxin- and glutathione-dependent peroxidases) [38-40]. Candida albicans and C. glabrata carry only one catalase gene (CTA1) [41, 42]. Since both stress and non-fermentable carbon source can induce the expression of CTA1, its regulation is a combination between two catalase genes which can be found in S. cerevisiae [43]. Though not yet unswervingly shown, the complex regulation and conservation of this enzyme in C. glabrata suggests a role in peroxide stress resistance in the host environment. In yeasts, a great majority of the almost 500 stress genes are under the control of four transcription factors: ScYap1 (the central component of the oxidative stress response regulated by $\mathrm{H}_{2} \mathrm{O}_{2}$ or diamine), ScSkn7 (important for peroxide stress protection and for the induction of TRX2, TRR1, TSA1, and CTA1 [44]), and ScMsn2/ScMsn4 $[45,46]$. The core response to oxidative stress consists of thioredoxin cofactor $\operatorname{Tr} 2$, glutathione peroxidase Gpx2, and catalase Cta1, thioredoxin peroxidases (Tsa1 and Tsa2), and thioredoxin reductases (Trr1 and Trr2). Finally, the transcription of the $C$. glabrata copper-zinc superoxide dismutase (SOD) genes, $S O D 1$ and $S O D 2$, is regulated in another way from yeast. Both $S O D$ genes are induced by carbon source depletion, whereas, significantly, SOD1 is expressed constitutively [47].

Surrounded fungal pathogens control their metabolism in the glucose-deficient environment inside the macrophage and adjust their expression profile towards genes involved in the employment of alternative carbon sources. Genes of the glycolytic pathway are repressed, whereas genes encoding for 
proteins are needed for gluconeogenesis, $\beta$-oxidation, glyoxylate cycle, autophagy, peroxisome proliferation, and amino and acetate transports are induced [48, 49]. Glucose sensing involves two antagonizing mechanisms, depending on the glucose availability or glucose limitation. Snfl, a protein kinase, which stimulates the transcription of glucose-repressed genes, plays a central role during glucose starvation in $S$. cerevisiae and C. glabrata. The presence and absence of glucose in C. glabrata leads to similar changes of transcription, as in $S$. cerevisiae [50]. To escape the host defense mechanisms, variations of the yeast morphology can permit the burst from phagocytotic cells. Candida glabrata is capable of detoxifying radical oxidative species and seems to disrupt normal phagosomal maturation, leading to the inhibition of phagolysosome formation and phagosome acidification [51]. In terms of starvation, $C$. glabrata autophagy is used for intracellular nutrient mobilization, being vital for its virulence. It is a highly controlled process and needs a number of factors for the correct recognition, packaging, and delivery of cargo to the vacuole [52-54]. Candida glabrata survives the defense mechanisms induced by the macrophage, including largely oxidative stress.

Host-pathogen interaction demands numerous crucial functions achieved by proteins of the cell wall, such as tissue adhesion, invasion and biofilm formation, protection from host defense mechanisms, triggering of the host immune system, and resistance to antifungal drugs [55]. Candida glabrata adherence to the host epithelial tissue is mainly mediated by a number of glycosylphosphatidylinositol (GPI)-linked adhesin genes [56, 57], some induced in C. glabrata cells from biofilms [58]. Its genome (ATCC 2001) covers 67 genes encoding putative adhesin-like GPI-modified cell wall proteins, including the Epa family with 17 members [59], and their expression is regulated. Moreover, C. glabrata cells carrying mutations in some loci show a rise in adherence to epithelial cells and are able to colonize organs more efficiently [60-62]. In fact, there are several factors tangled in the development of $C$. glabrata infection. Naturally, these features promote the pathogenicity performing together and depend on the species characteristics itself and the host physiology conditions, specifically the state of its immune system [62].

A model using a reconstituted human oral epithelium (RHOE) infected only with C. glabrata or simultaneously with $C$. glabrata and C. albicans showed that $C$. glabrata strains originating from the oral, vaginal, and urinary tract were able to colonize the tissue but in a strain-dependent manner. Single infection with $C$. glabrata showed no invasion of the RHOE but mixed infection showed that $C$. albicans enhanced the invasiveness of C. glabrata [63] (Fig. 1). The results obtained by these authors demonstrated an enhanced invasion and increased tissue damage caused by mixed $C$. glabrata and C. albicans infections, which has important clinical significance and highlights the need to better identify Candida species involved in oral candidosis.
Jayatilake et al. [64] also used an RHOE model to study host interaction and the virulence factors in oral candidiasis induced by $C$. albicans and NCACs, using mutated species. All $C$. albicans isolates invaded the tissue over $48 \mathrm{~h}$. The invasive potential of hyphal and SAP (secreted aspartyl proteinases) mutants was similar to the parent wild-type isolate at $12 \mathrm{~h}$, although after $24 \mathrm{~h}$, their invasion was dissimilar. NCACs and hyphal mutants were all non-invasive and the second most pathogenic group comprised $C$. albicans with $C$. glabrata. This study supports the theory that the conversion from the blastospore phase to the hyphal phase is an important virulence attribute of $C$. albicans, in comparison with NCACs, showing also that, for these species (including $C$. glabrata), it is necessary to focus on other features in order to understand and to contour NCAC species infections. There are no in vivo studies concerning $C$. glabrata infection. In vivo models can give additional information on what is occurring inside the cell, organ, and/or organism.

\section{Virulence factors in Candida glabrata}

Decades ago, it was assumed that yeasts passively contributed to the process of pathogenesis in the establishment of a fungal infection. Consequently, organic weakness or an immunocompromised host was considered the only mechanism responsible for the establishment of opportunistic infection. Nowadays, this concept has been modified and it is known that these organisms dynamically participate in the pathophysiology of the disease process using mechanisms of aggression called virulence factors $[2,65]$. Moreover, the pathogenicity of Candida species is attributed to certain virulence factors, such as the ability to evade host defenses by filamentous forms, adherence ability, biofilm formation capacity (on host tissue and on medical devices), and the production of tissuedamaging hydrolytic enzymes such as phospholipases, lipases, and hemolysins $[2,65]$.

The fairly non-pathogenic nature of $C$. glabrata in animal models suggests that it has few virulence attributes; nevertheless, its high mortality rate and rapid dissemination points to the opposite. However, it is known that $C$. glabrata possess several factors tangled in the development of an infection. Naturally, these features promote the pathogenicity performing together and depend on the C. glabrata characteristics itself and the host physiology conditions, specifically, the state of its immune system [65].

Adhesion and biofilm formation

Candida glabrata is capable of colonizing host tissues as well as abiotic surfaces, where it develops as a multilayered biofilm structure [66, 67], despite not being able to form filaments. An important factor correlated with the adhesion ability of 
Fig. 1 Single (a) and coinfection (b) of Candida glabrata and Candida albicans of a reconstituted human epithelium after $12 \mathrm{~h}$, assessed by laser scanning microscopy. The arrow indicates $C$. glabrata cells invading the epithelium
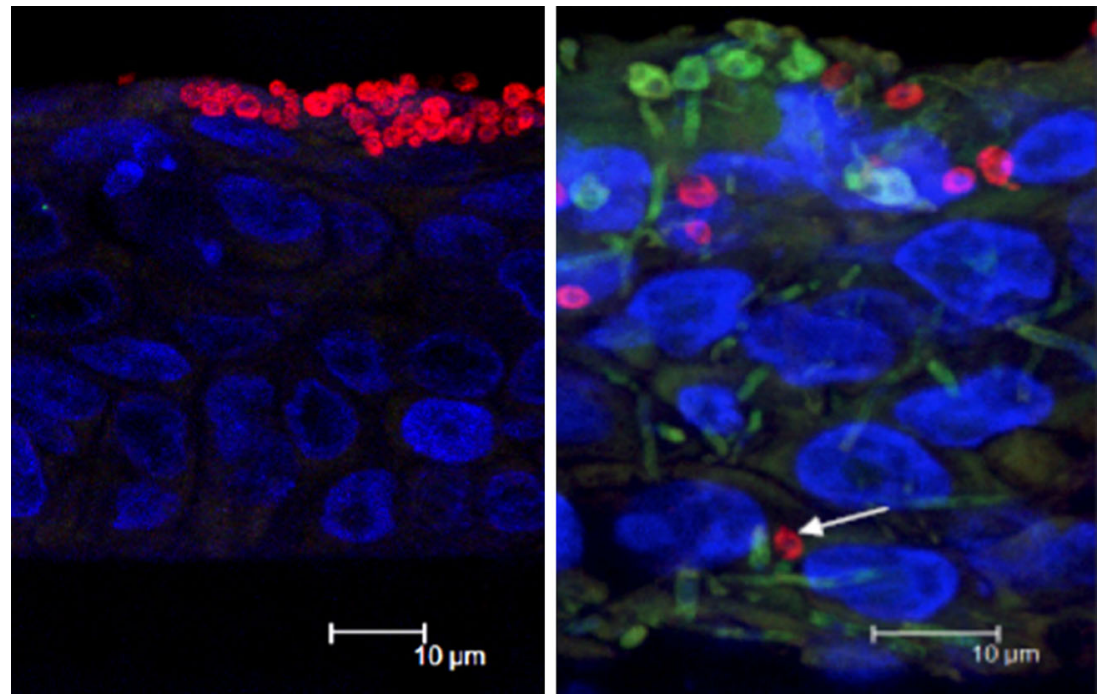

A

B
Candida species is the presence of specific proteins on its cell wall, namely, adhesins. In C. glabrata, a major group of adhesins is encoded by the Epa (epithelial adhesin) gene family [68]. The overall structure of Epa proteins is similar to that of the Als (agglutinin-like sequence) proteins of $C$. albicans. Although there are few studies concerning $C$. glabrata Epa proteins, it is known that Epalp is a $\mathrm{Ca}^{2+}$ dependent lectin that binds to $\mathrm{N}$-acetyllactosaminecontaining glycoconjugates [69]. Furthermore, despite the large number of EPA genes, it has been shown that the deletion of merely EPA1 reduces in vitro adhesion [68]. However, although EPA6 is not expressed in vitro, its expression increases during in vivo urinary infection, suggesting that C. glabrata is able to adapt to different environmental conditions $[60,64]$.

EPA6 and its close paralogue EPA7 are located in subtelomeric regions and their transcription is regulated by Sir4p and Rifl $p$, two proteins involved in subtelomeric silencing. Biofilm growth conditions induce the transcription of EPA6 and EPA7: this is dependent on the presence of an intact subtelomeric silencing machinery and is independent of the Mpk1p signaling pathway. Finally, the kinase Yak1p is required for the expression of both adhesin genes and acts through a subtelomeric silencing machinery-dependent pathway [67].

Biofilm forming ability may confer C. glabrata an ecological advantage, aiding survival as commensals and pathogens of humans by allowing them to evade host immune mechanisms, resist antifungal treatment, and withstand the competitive pressure from other microorganisms [70]. Biofilm formation in C. glabrata, besides possibly being a key factor for the survival of these species, may also be responsible for them being particularly well adapted to the colonization of tissues and indwelling medical devices. Comparing with the other Candida species, C. glabrata displays the lowest biofilm metabolic activity, despite having the highest number of biofilm cultivable cells. Likewise, the metabolic activity of resuspended C. glabrata biofilm and planktonic cells is lower than that of the other species [70]. Thus, generally, $C$. glabrata biofilms have less total biomass and its strains show similar biofilm forming ability, in opposition to $C$. parapsilosis and C. tropicalis. Candida glabrata biofilms often display a structure of a multilayer with blastoconidia intimately packed or constituted by clusters of cells with, in both cases, total absence of pseudohyphae and hyphae (Fig. 2). Remarkably, biofilm matrices of $C$. glabrata have relatively higher quantities of protein and carbohydrate (in some cases, five times higher) compared with other NCACs $[2,64,70]$.

Biofilm conditions and high cell density are adhesion inducers, activating EPA6, whereas EPA1 is triggered typically in the lag phase $[67,68]$. This complex regulation of adhesin genes in C. glabrata is reminiscent of the greatly and complicated regulation of $S$. cerevisiae flocculation $(F L O)$ genes. Indeed, FLO11 is one of the genes regulated by the Swi/Snf complex [71, 72]. Thus, reliable with the knowledge that adhesion of $C$. glabrata to host epithelial tissue plays an important role in virulence, the genes FLO1, FLO5, and FLO10 were studied and were found to be Pdr1-dependent [73]. In C. glabrata, FLO10 (named EPA1) is essential for effective in vitro adherence to human epithelial cells, evidencing a role for EPA1 in adherence to abiotic materials [69]. FLO5 has been described as a member of the Epa family of adhesion proteins in C. glabrata; however, its role in adherence has not been openly studied. The link between $F L O$ and $E P A$ genes prove that its regulation may control the adherence of Candida species during the host interactions, conferring distinct adhesion profiles towards human proteins and cells $[74,75]$. This regulation is variable among species and even between strains of the same species [75]. 
Fig. 2 Candida glabrata American Type Culture Collection (ATCC) 2001 48-h biofilm formation in Sabouraud Dextrose Broth (SDB).

Magnification $1,000 \times($ left $)$ and $3,000 \times($ right $)$
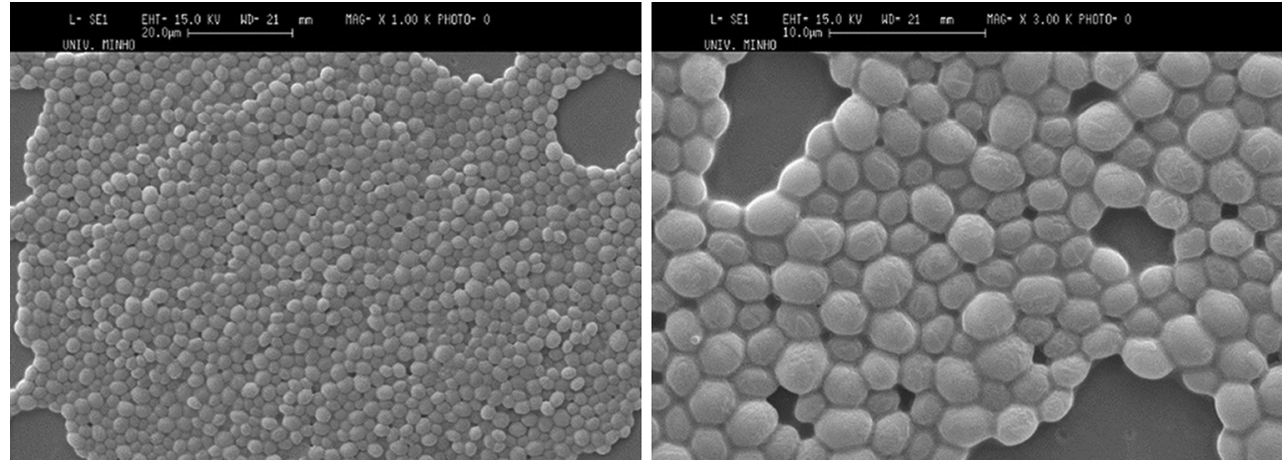

A study using isolated mutant strains allowed the identification of four genes involved in biofilm formation: silent information regulator (SIR4), telomere-binding (RIF1), EPA6, and serine-threonine protein kinase, YAK1 [69]. Moreover, like in C. albicans and C. parapsilosis, in C. glabrata, the transcription factor Bcr1 is a dominant regulator of the biofilm development, though the full extent of its regulation remains unknown [76].

\section{Enzyme production}

In the Candida genus, the so-called virulence factors comprise not only the adhesion and biofilm formation, but also the ability to destroy host tissues, which may be facilitated by the release of hydrolytic enzymes into the local environment. The general secretion of enzymes, such as proteases, phospholipases, lipases, and hemolysins, help the yeasts to survive and replicate within macrophages, being able to destroy the epithelium. As mentioned earlier, C. glabrata do not produce proteases, in opposition to the rest of the Candida species [69, 70]. In fact, there is one study that has shown that this species is capable of proteinase production, but the type of proteinase was not specified [77].

Phospholipases (PLs) hydrolyze phospholipids into fatty acids and their production contribute to host cell membrane damage, promoting cell damage or exposition of receptors that facilitate adherence. Candida glabrata produces phospholipases, which clearly promotes a greater and powerful interface with the host mucosae, destroying it and endorsing an effective invasion of the tissues involved [78-80].

Lipases are tangled in the hydrolysis of triacylglycerols, which are also produced by $C$. glabrata. In C. albicans, ten genes encoding for lipases have been identified and it has been shown that mutants were significantly less virulent in a murine intravenous infection model. Sequences similar to C. albicans (LIP1-10) were also detected in C. tropicalis, but not in $C$. glabrata [78-82].

Newly, some authors described that NCAC species, such as C. glabrata, have been able to degrade hemoglobin using hemolysins in order to obtain iron [83, 84]. Like other Candida species, C. glabrata can grow in the host by degrading hemoglobin and extracting the elemental iron from host cells for metabolic processes. The assembly of this hemolytic factor may be regulated by the presence of glucose in the growth medium. Candida glabrata and other NCAC species are able to produce hemolysins in vitro, bringing partial or total erythrocyte lyses, though the extent of this is both strain- and species-dependent $[85,86]$. Although hemolysins are known to be putative virulence factors backing pathogenicity in Candida species, the genetic expression of hemolytic activity in C. glabrata is poorly understood. Luo et al. [85] revealed that a hemolysin-like protein (HLP) gene was allied with the hemolytic activity of $C$. glabrata.

\section{Drug resistance mechanisms in Candida glabrata}

\section{Antifungal drug mechanisms}

As already remarked, there are many antifungal classes, which have different mechanisms of fungicidal or fungistatic action on Candida species. Azoles, like fluconazole, itraconazole, ketoconazole, miconazole, voriconazole, posaconazole, and rosaconazole, are able to block the ergosterol biosynthesis by the inhibition of lanosterol $14 \alpha$-demethylase, leading to a diminished ergosterol production. Moreover, they are responsible for the lack of ability to build and renew sterols in the cellular membranes, changing the membrane fluidity and function of vital processes such as signaling, transport, exocytosis, and endocytosis. Polyenes, such as amphotericin B, nystatin, and pimaricin, link to the ergosterol molecules, resulting in pores on the cell wall and, thus, increasing cell permeability. Antimetabolite antifungal drugs, such as 5fluorocytosine, inhibit RNA function and, finally, the allylamines and a chitin synthase inhibitor, the nikkomycin Z. Figure 3 summarizes the mechanisms of antifungal action.

Each antifungal class uses distinct means to eradicate or inhibit the growth of fungal pathogens. The mechanisms of antifungal resistance are categorized as primary or secondary and are related to intrinsic or acquired characteristics of the fungal pathogen, including interference with the antifungal 
Fig. 3 Mechanisms of action of antifungal drugs

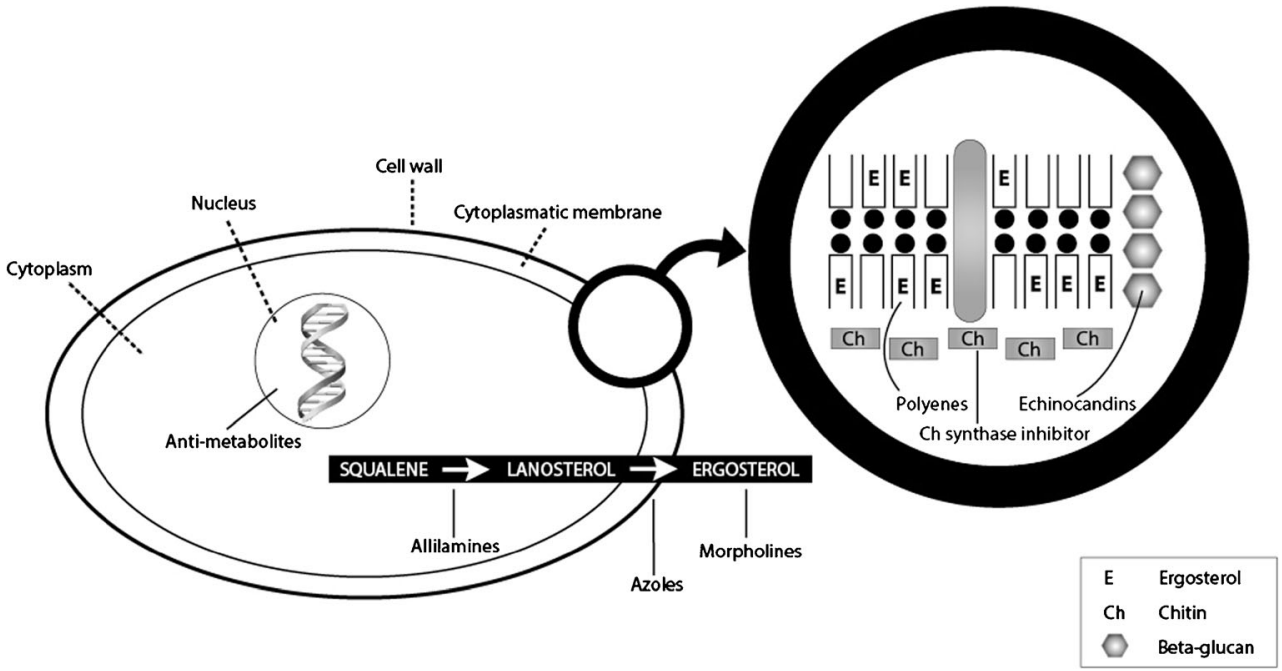

mechanism of the respective drug or the decrease in target drug levels [15].

Genomic plasticity is an important machinery for adaptation to environmental signs, such as host responses and antifungal drug pressure in many fungi, including $C$. glabrata . For example, the C. glabrata genome has lost genes involved in galactose and sucrose assimilation, phosphate, nitrogen, and sulfur metabolism, as well as thiamine, pyridoxine, and nicotinic acid biosynthesis $[12,15]$.

In 2012, Bader et al. [87] analyzed the derivatives in $C$. glabrata strains' genomes. These were shown to be indistinguishable by multilocus sequence typing, but dissimilar phenotypic groups that correlated with specific karyotypic changes were also detected. Alterations that can significantly affect phenotypic properties, for example, in the quantitative changes in adhesin genes expression and the cell wall carbohydrate composition, could also be noticed rather than subtelomeric genes loss or differences in the number of macrosatellite repeats within adhesin genes. It is important to highlight that these phenomena, such as chromosomal aberrations and functional adaptations, may occur during infection and under antimicrobial therapy, but also under laboratory conditions deprived of extreme selective pressures. Rai et al. [88] showed that chromatin alterations could happen as essential strategies of survival, which facilitates a reprogramming of cellular energy metabolism in macrophage-internalized C. glabrata cells, and provide protection against DNA damage.

So, C. glabrata, like all Candida species, possess the ability to answer to the environmental alterations aimed to adapt to the presence of antifungal agents and, in this way, provide protection against antimicrobial therapies [62].

Antifungal resistance is both complex and multifaceted. It can be inducible in response to a compound or be an irreversible genetic change resulting from prolonged exposure. In detail, these include alterations or even an overexpression of target molecules, active extrusion through efflux pumps, limited diffusion, tolerance, and cell density, which are all characterized mechanisms utilized by fungi to combat the effects of antifungal treatments [89]. Planktonic cells generally rely on irreversible genetic changes to maintain a resistant phenotype, whereas biofilm cells are able to persist due to their physical presence and the density of the population, which provides an almost inducible resistant phenotype irrespective of defined genetic alterations. Thus, C. glabrata has an intrinsically reduced susceptibility to commonly used antifungal drugs due to different properties, which are summarized in Table 2.

Active efflux from procaryotic as well as eucaryotic cells strongly modulates the activity of a large number of antifungals. Inside the group of primary active transporters, predominant in eucaryotes, six families belonging to the ATP-binding cassette superfamily, and including the P-glycoprotein in the $M D R$ (multidrug resistance) group and the MRP (multidrug resistance protein), have been recognized as being responsible for antibiotic efflux $[90,91]$. Within the class of secondary active transporters (antiports, symports, and uniports), ten families of antibiotic efflux pumps have been described and distributed in five superfamilies [SMR (small multidrug resistance), MET (multidrug endosomal transporter), MAR (multiantimicrobial resistance), RND (resistance nodulation division), and MFS (major facilitator superfamily)]. In eucaryotes, antibiotic efflux pumps modulate the accumulation of antimicrobials in phagocytic cells and play major roles in their transepithelial transport [91].

Table 3 summarizes the genes discussed above and others that are involved in C. glabrata resistance to antifungal drugs.

\section{Azoles and resistance}

Candida glabrata grows only as a yeast form in vivo and its adhesion is relatively weak [91-93], so it is believed that the increase of C. glabrata infections is due to its intrinsically low 
Table 2 Summary of the most relevant factors involved in Candida glabrata antifungal resistance

\begin{tabular}{|c|c|c|}
\hline Factor & Description & References \\
\hline Tolerance & $\begin{array}{l}\text { Pathogenic fungi encounter and bear a range of physiological stresses from } \\
\text { different environments: temperature changes, ionic stress, changes in } \\
\text { osmolarity, and oxidative stress (e.g., phagosomes of neutrophils) }\end{array}$ & {$[118]$} \\
\hline Environmental stress & $\mathrm{pH}$, temperature, oxygen availability, etc. & {$[119,121-125]$} \\
\hline Cell density & Mature biofilms, whilst densely populated, exhibit spatial heterogeneity & {$[119,126,127]$} \\
\hline Efflux pump-mediated resistance & Exocitosis of the drug & {$[128-134]$} \\
\hline Extracellular matrix & $\begin{array}{l}\text { Presence of extracellular matrix, which is an essential characteristic of } \\
\text { fungal biofilms, providing the cells with protection from hostile factors }\end{array}$ & {$[21,34,135]$} \\
\hline Genetic alterations & Like overexpression of genes related with drug targets & {$[135-141]$} \\
\hline Persister cells & $\begin{array}{l}\text { These are "dormant variants of regular cells that form stochastically in microbial } \\
\text { populations and are highly tolerant to antibiotics". They are a vital mechanism } \\
\text { of resistance in chronic infections }\end{array}$ & {$[24,142-144]$} \\
\hline
\end{tabular}

susceptibility to azoles, including the imidazoles (e.g., miconazole) and the oral-parenteral triazoles (e.g., fluconazole, voriconazole) [94]. The development of $C$. glabrata infections parallels the introduction, in the early 1990s, of triazoles and over-the-counter imidazoles. Acquired resistance results from rare mutations that are selected by drug pressure [95]. All the genes involved in the biosynthesis of ergosterol are expected to be upregulated in case of the presence of azole molecules. Nevertheless, ERG genes are the ones more focused on in studies. Between them are ERG1, ERG3, ERG6, ERG7,

Table 3 Genes of Candida glabrata involved in resistance to antifungal drugs

\begin{tabular}{|c|c|c|}
\hline Gene & Function & References \\
\hline$E P A$ family & Adhesion & [67-69] \\
\hline SIR3, RIF1 & & {$[69]$} \\
\hline$E R G$ family & Ergosterol biosynthesis & {$[101]$} \\
\hline PDRl & $\mathrm{ABC}$ transporters & {$[102]$} \\
\hline$C D R 1-4, S N Q 2$ & & [101-103] \\
\hline$B C R 1$ & Biofilm formation & {$[104]$} \\
\hline$F K S 1-2$ & $\beta-1,3$ glucan biosynthesis & $\begin{array}{l}{[61,101,} \\
\quad 105-108]\end{array}$ \\
\hline YPS family & $\begin{array}{l}\text { Adhesion } \\
\text { Colonization }\end{array}$ & [109] \\
\hline CTA1 & Oxidative stress processes & {$[43,110]$} \\
\hline$A T G 11, A T G 17$ & Phagocytosis survival & {$[43]$} \\
\hline$M D R 1$ and $F L R 1$ & $\begin{array}{l}\text { Major facilitator family; MFS } \\
\text { transporters }\end{array}$ & [101] \\
\hline Krel and $S K N 1$ & $\beta-1,6$ glucan biosynthesis & {$[101]$} \\
\hline$A C E 2$ & General virulence & {$[111-114]$} \\
\hline$A R O$ & $\begin{array}{l}\text { Pigmentation } \\
\text { Oxidative stress processes }\end{array}$ & [115] \\
\hline $\begin{array}{l}\text { ZAP1, GCAL1, } \\
\text { ADH5, CSH1 }\end{array}$ & Extracellular matrix regulators & {$[101]$} \\
\hline Afu MDR4 & $\mathrm{ABC}$ transporters & {$[101]$} \\
\hline$M C K 1$ & MAPK & {$[101]$} \\
\hline HSP9O & Heat shock processes & {$[101]$} \\
\hline
\end{tabular}

$E R G 9$, and especially ERG11. ERG11 is involved in the reaction that converts lanosterol into 4,4-dimethylcolesta-8, 14,24-trienol. This gene is noticeably more referred as the central point on the increase of ergosterol production, in response to the azole attack to the Candida cell membrane, especially in C. glabrata, which has great ease to acquire azole resistance $[90,95]$. Potential mechanisms to azole resistance include a small affinity of its lanosterol $14 \alpha$-demethylase or a high ability to upregulate ERG11 (ergosterol biosynthesis genes), CDR1, and PDR1 expression following azole exposure [48]. Acquired resistance results from rare mutations that are selected by drug pressure [95-97]. Mitochondrial dysfunction is another of the possible mechanisms by which azole resistance can occur in C. glabrata. Moreover, the development of the "petite mutants" (cells with mitochondrial DNA deficiency) upregulates the ATP-binding cassette $(A B C)$ transporter genes, exposes amplified resistance to azoles, and endears a drastic improvement of fitness. However. there is a lack of information about the real involvement of the "petite mutants" in azoles' Candida resistance [98]. However, by screening a library of 9,216 random insertion mutants, Kaur and colleagues [99] identified a set of 27 genes, which, upon mutation, confer changed fluconazole susceptibility in $C$. glabrata. These genes comprise those belonging to the family of ABC transporters (PDR5 and PDR16), genes involved in retrograde signaling from mitochondria to nucleus (RTG2), and genes involved in diverse cellular functions (activation of RNA polymerase II transcription, calcium homeostasis, ribosomal biogenesis and mitochondrial function, nuclear ubiquitin ligase function, and cell wall biosynthesis). Those authors studied two kinds of mutants, the first being the Cch1-Mid1, defective in calcium uptake in response to fluconazole exposure, in which they noticed that the strains flawed in a putative plasma membrane calcium channel were discreetly more susceptible to fluconazole but revealed a significant loss of viability upon prolonged fluconazole exposure, proposing that calcium signaling is necessary for the survival of azole stress 
in C. glabrata. Thus, in the absence of $\mathrm{Ca}^{2+}$ signaling, fluconazole has a fungicidal rather than a fungistatic effect on $C$. glabrata. Finally, in the second set of mutants, defective in mitochondrial assembly and organization, the cells exhibited very high levels of fluconazole resistance, indicating an existence of a mechanism for the reversible loss of mitochondrial function that does not involve loss of the mitochondrial genome and that C. glabrata can shift between states of mitochondrial competence and incompetence in response to fluconazole exposure [100]. Candida glabrata calcineurin mutants exhibit increased susceptibility to both azoles and cell wall-damaging agents and are also attenuated in virulence. While a mutant lacking the transcription factor Crz1, a calcineurin-regulated transcription factor, displayed a cell wall-associated phenotype intermediate to that of the calcineurin mutant and was modestly attenuated in virulence, it did not show amplified azole susceptibility, suggesting that calcineurin regulates both Crz1-dependent and -independent pathways, depending on the type of stress [100].

Candida glabrata has intrinsic azole resistance or acquires, very easily, drug resistance during prolonged azole therapy, by undergoing mutation either in vitro or in vivo [101]. Several $A B C$ transporters, including Cdr1p, Pdh1p (also known as $C D R 2$ ), Yor1p, and Snq2p, contribute to xenobiotic drug efflux. The transcription factor Pdrlp is the principal regulator of $A B C$ transporter gene expression and has been found to be a key component of pleiotropic drug resistance $(P D R)[102,103]$. A C glabrata open reading frame (CAGL0I02552g) codes for a protein conserved among hemiascomycete binuclear zinc cluster proteins, showing a common ancestry and, probably, an important function in these yeasts. Pdrlp has been found to form a heterodimer with Stb5p in S. cerevisiae. Transcriptional analysis signposted a shared regulon among the homologues of these two genes, PDR1 and STB5, in C. glabrata, and many of the genes upregulated by the overexpression of PDR1 were upregulated by the deletion of STB5. Thus, the PDR 1 overexpression and STB5 deletion are correlated [104, 105]. The overexpression of STB5 in C. glabrata represses azole resistance, while the deletion of STB5 produces a shy intensification in resistance. Expression analysis assays established that STB5 shares many transcriptional targets with $P D R 1$ but, unlike the second, it is a negative regulator of pleiotropic drug resistance (including the $A B C$ transporter genes CDR1, PDH1, and YOR1) [105, 106].

Transcript profiling with microarrays showed that more than 385 genes are differentially regulated by a selected number of the gain-of-function (GOF) mutations expressed in the same genetic background, with a minimal overlap in coregulated genes. CDRI and PUPI (for PDRI upregulated and encoding a mitochondrial protein) were generally upregulated by all tested GOFs. While both genes mediated azole resistance (with in vitro and in vivo expression, though to different extents), their deletions in an azole-resistant isolate managed a decline in virulence and a decrease in tissue load. Their individual overexpression was showed to partially restore phenotypes obtained in clinical isolates [106].

$A P 1$ ortholog encodes a transcription factor involved in various stress responses. Chen et al. [107] showed that $A P 1$ plays a critical role in the reaction to various stresses in $C$. glabrata and reduces the stress through transcriptional activation of its target genes, including FLR1. They demonstrated that the deletion of FLR1 in C. glabrata only resulted in increased sensitivity to benomyl, diamide, and menadione, but not 4-NQO, cycloheximide, or fluconazole.

The aldo-keto reductase superfamily is known to be upregulated in the resistant $C$. glabrata clinical isolates. Reverse transcription quantitative polymerase chain reaction (RTqPCR) reveals $A K R$ mRNA expression about twice that seen in the sensitive isolates. Thus, this overexpression of the $A K R$ gene is associated with amplified fluconazole and itraconazole resistance, suggesting that upregulation of the $A K R$ gene might give a new insight into the mechanism of azole resistance $[61,108]$.

\section{Echinocandins and resistance}

Echinocandins are front-line agents against invasive candidiasis (IC), but conjectures for echinocandin therapeutic failure are arising; however, they are not well demarcated. This class of antifungal agents is considered to be the first-line treatment of IC due to C. glabrata, but this NCAC species has already been described as developing reduced susceptibility to caspofungin during prolonged therapy. Studies involving sequentiation of hot spots, known to confer echinocandin resistance, revealed an $\mathrm{F} 659 \mathrm{~V}$ substitution within the FKS2 region of the glucan synthase complex [109].

Recently, strains of C. glabrata have also been detected to be resistant to both fluconazole and the echinocandins. In these strains, an acquired mutation in FKS1 or FKS2 was detected [110]. These mutations in Candida FKS genes, which encode the enzyme targeted by echinocandins, end in elevated minimum inhibitory concentration (MIC) and have been linked to therapeutic failures. Micafungin MICs of $C$. glabrata FKS hot spot mutant isolates were perceived to be less elevated than those obtained for the other echinocandins, showing that the efficacy of micafungin could be differentially dependent on specific FKS genes mutations [111]. Interestingly, in another study, echinocandin MICs and FKS1 and FKS2 mutations among C. glabrata isolates were correlated with echinocandin therapeutic responses. FKS mutations were detected and the median caspofungin and anidulafungin MICs were higher for patients who failed therapy [112]. In another study [113] from patients with C. glabrata bloodstream infections at Duke University Hospital in Durham, NC, the treatment outcome (using anidulafungin, caspofungin, and 
micafungin) was correlated with the MIC results and the presence of FKS1 and FKS2 gene mutations. The results showed that the resistance to echinocandins increased from 4.9 to $12.3 \%$ between 2001 and 2010 . Moreover, among the 78 fluconazole-resistant isolates, $14.1 \%$ were resistant to one or more echinocandins. Almost $8 \%$ of the isolates had an FKS mutation, which appeared due to a prior echinocandin therapy, and virtually all of them demonstrated intermediate or resistant MICs to an echinocandin (failure or recurrence of infection). Additionally, the new Clinical and Laboratory Standards Institute (CLSI) clinical breakpoints differentiate wild-type from $C$. glabrata strains bearing clinically significant FKS1/FKS2 mutations.

\section{Polyenes and resistance}

The molecular mechanisms that lead to polyene resistance are still poorly documented, especially in C. glabrata strains. In a previous study [114], a clinical isolate of $C$. glabrata showed lower ergosterol content in its membrane than the wild-type, and this low content was established to be linked to a nonsense mutation in the ERG6 gene and to the induction of the ergosterol biosynthesis pathway. Variations of the cell wall were also perceived, accompanied by improved susceptibility to cell wall-perturbing agents, with a high rate of cell mortality. In conclusion, the nonsense mutation detected in the ERG6 gene of this isolate led to a decrease in ergosterol content [114].

Moreover, an other clinical isolate of C. glabrata with a poor susceptibility to polyenes and recovered from a patient treated with amphotericin B was analyzed by Vandeputte et al. [115], demonstrating that a mutation in the ERG6 gene leads to a reduced susceptibility to polyenes and to subsequent changes in the sterol content of the plasma membrane. Thus, a deficiency of ergosterol and an accumulation of late sterol intermediates was shown, highlighting a defect in the final steps of the ergosterol pathway. Sequencing exposed a unique missense mutation in $E R G 6$, leading to the substitution of a cysteine by a phenylalanine in the corresponding protein. Later, a real-time PCR proved an overexpression of the genes that encode enzymes involved in late steps of the ergosterol pathway. The complementation of this strain with a wild-type copy of the ERG6 gene reestablished susceptibility to polyenes and a classical morphology [115].

\section{Other antifungal agents' resistance}

Allylamines: A study developed by Vermitsky and Edlind [103] showed that the treatment with terbinafine, which targets the enzyme squalene epoxidase in the ergosterol biosynthetic pathway, found upregulation on ERG11 as previously reported but, unlike in the azoles case, had a minimal effect on $C D R 1$ and $P D H 1$.
Histatin 5: In order to develop new antimycotics with possibly diverse cellular targets, histatins, a group of human salivary cationic proteins, were studied [116-120]. Histatins are extremely effective against diverse classes of fungi, but they are significantly less effective against $C$. glabrata, being hypothesized that $C$. glabrata might escape histatin 5 activity by applying fermentative pathways, since, theoretically, glucose can either be fermented or assimilated. Furthermore, $C$. glabrata is a Crabtree-positive fungus [121], and its respiration could be negatively affected by certain levels of glucose [122]. The results confirm an apparently fundamental and extensive resistance of C. glabrata to histatin 5, though the resistance to histatin 5 is not related to the resistant mechanisms of azoles.

Pathogenic fungi represent a special problem in the clinic, as the range of drugs that can be used to treat these kinds of infections is restricted. This situation is further complicated by the presence of robust inducible gene networks encoding different proteins that confer tolerance to many available antifungal drugs [123]. Moreover, it is important to state that C. glabrata has frequently been reported as exhibiting variable karyotypes between isolates [124-131] and several works have shown that these karyotypes are rather stable, hypothesizing that the karyotype of virulent species is more stable than avirulent species [132]. The major karyotypic differences between $C$. glabrata strains are related to a small number of chromosomal translocations. Along with variation in the subtelomeric EPA genes, the other genomic rearrangements are copy number variations in tandem gene repeats, encoding putative or known cell wall proteins [125].

\section{The role of biofilms in Candida glabrata resistance}

As already seen, most microorganisms exist in nature as complex communities, the biofilms, which are attached to surfaces rather than isolated free-floating planktonic organisms. These structurally and functionally complex communities consist of one or more microbial species encased in an extracellular polymeric substance, and attached to one another or to a solid surface [132]. A broad variety of environmental factors contribute to the initial surface attachment of Candida cells: $\mathrm{pH}$, temperature, osmolarity, presence of bacteria, the flow of the surrounding medium (urine, blood, saliva, and mucus), presence of antimicrobial agents, and host immune factors [133-137]. Fungal biofilms are formed in different phases of development, including arriving at an appropriate substratum, adhesion, colonization, extracellular matrix production, biofilm maturation, and dispersal [125, 134, 138-140].

Comparing planktonic cells to biofilms, the latter are much more resistant to antimicrobials, and are thought to be involved in up to $65 \%$ of all human microbial infections [141]. It has recently been proved that the cells that detach 
from the biofilm have a greater association with mortality than equivalent planktonic yeasts [142]. As yet, there appears not to be one specific resistance factor responsible for the increased recalcitrance to antifungal agents exhibited by biofilms. Instead, biofilm resistance is a complex multifactorial phenomenon, which still remains to be fully elucidated and understood. Different mechanisms may be responsible for the intrinsic resistance of Candida biofilms and specifically $C$. glabrata. These include the following: (i) high density of cells within the biofilm; (ii) effects of the biofilm matrix; (iii) decreased growth rate and nutrient limitation; (iv) expression of resistance genes, particularly those encoding efflux pumps; and (v) presence of "persister" cells.

The cell density is an important factor for antifungal resistance in biofilms, particularly for azoles. One study showed that both planktonic and biofilm cells exhibit sensitivity to azoles with low numbers of cells $\left(10^{3}\right.$ cells $\left./ \mathrm{mL}\right)$, becoming increasingly resistant with an improved density. In dense biofilms, there is a cooperation between cells through processes named "quorum sensing", enabling organizations to communicate and coordinate their behavior by the secretion of signaling molecules, which are dependent on the population density [143, 144].

Regarding the biofilm matrix, one supposition is that the existence of the matrix reduces the penetration of drugs through the establishment of a diffusion barrier, as an ionexchange resin, binding charged antibiotic molecules [24], like antifungals. Moreover, it is known that planktonic cells generally rely on irreversible genetic changes to maintain a resistant phenotype, whereas biofilms are able to persist due to their physical presence and the density of the population, which provides an almost inducible resistant phenotype irrespective of defined genetic alterations [144]. Candida albicans experiments with resuspended sessile cells recovered from mature biofilms indicated that, when tested as freefloating cells, they were also resistant to fluconazole and amphotericin B challenge, but not to the same level as that found in the mature biofilms from which they were derived. Moreover, in mixed biofilms, the extracellular matrix produced by bacterial cells was shown to retard the diffusion of the antifungal agents, but poor penetration did not account for the drug resistance of Candida biofilm cells. Overall, these results seem to indicate that, although the extracellular matrix plays a partial role in sessile resistance, the influence of other factors is also significant [144].

In fact, the ability to form biofilms is intimately associated with the ability to cause infection and, so, it should be considered an important virulence determinant during candidosis. The biofilm lifestyle results in antifungal drug resistance and protection from host defenses, both of which carry important clinical repercussions. Molecular studies on biofilm formation have begun to shed light on the driving forces behind the transition to the biofilm mode of existence, which, in the future, may offer a potential therapeutic avenue. The application of powerful DNA microarray and proteomic technologies should facilitate a more detailed analysis of the biofilm lifestyle [145, 146].

Some biofilm formation genes are beginning to be brought up by researchers concerning different roles in this process. Between them, we can find the peroxisomal catalase (CTA1), the biosynthesis and degradation of tyrosine genes $(A R O)$, the muscle creatine kinase $(M S K)$, the heat shock protein 90 (HSP90), the sphingolipid biosynthesis (SKN1 and KRE1), $S I R, R I F$, and, finally, the extracellular matrix regulators: zinc-regulated genes $(Z A P 1)$, g-carbonic anhydrase (GCAL1), alcohol dehydrogenase (ADH5), and also cell surface hydrophobicity (CSH1) [144, 145].

The immunoevasion and intracellular persistence of $C$. glabrata may be a key factor in the capability of this species to persist in the course of multiple antifungal treatments and develop multidrug resistance. Second, changes in the cell wall associated with antifungal resistance often favor evasion for the host immune response $[67,72]$.

Lastly, extracellular polysaccharides are crucial elements of the biofilm matrix of many microorganisms. $\beta-1,3$ glucan, a very important polysaccharide in yeast, has been associated to biofilm protection from antifungal agents. The authors [147] identified three glucan modification enzymes that deliver glucan from the cell to the extracellular matrix, playing a biofilm-specific role, by mediating the delivery and organization of mature biofilm matrix. The enzymes consist of two glucan transferases and an exoglucanase, encoded by $B G L 2$, $P H R 1$, and $X O G 1$, respectively. The enzymes did not appear to affect the cell wall glucan composition of biofilm cells, nor are they necessary for filamentation or biofilm formation. Later, they also revealed that mutants missing these genes exhibit higher susceptibility to fluconazole during biofilm growth only. Transcriptional analysis and biofilm phenotypes of strains with multiple mutations propose that these enzymes allocate matrix downstream of the primary $\beta-1,3$ glucan synthase encoded by FKS1 [147].

The responses of organisms to stress have been recognized as antifungal resistance mechanisms of biofilms. Fungi are faced with different types of physiological stress from the surrounding environment, including changes in temperature or nutrients, ionic stress, changes in osmolality, and oxidative stress. These receptors are detected by a number of cells which induce responses by signaling pathways [148]. A study with C. glabrata showed that there is a positive regulatory protein of the stress response in biofilms of this kind, shown in the heat shock proteins (Hsp12p) and other stress proteins (Trx1 and Pep4) [149]. Persister cells are an important mechanism of resistance in chronic infections [144], which has received some attention in fungal biofilms. They are variants dormant in normal cells formed occasionally in microbial populations which are highly tolerant to antimicrobial agents. The first 
study of persister cells in Candida was performed with $C$. albicans, where such cells were detected only in biofilms. In this study, re-inoculation of cells that survived the destruction of biofilms with amphotericin B produced a new biofilm with a new subpopulation of persister cells, suggesting that these cells were not mutants but wild-type phenotypic variants and that the binding to a substrate initiated the dormancy state. Subsequently, a study with isolated persister cells of $C$. glabrata demonstrated that prolonged and ineffective antifungal therapy may be beneficial for the biofilm and its effect may be responsible for the failure and recurrence of fungal infections [150-153].

\section{Main research to develop regarding Candida glabrata}

Unfortunately, there are still several issues to explore regarding the course of infection by $C$. glabrata. Among them, we highlight the following avenues:

- Definition of the true role of FLO genes, which can bring useful answers regarding the adhesion process during the biofilm production;

- Introduction of the in vivo studies. The in vivo cells contain several types of machinery and molecules that can be helpful to the experiment. The in vivo approach could also be important to the evolution of hostinteraction research and the definition of new tactics regarding the strategies of remission of the C. glabrata pathologies;

- Revisions on the topic of the genes involved directly on the biofilm formation. Their role is still not well elucidated and could yield the key to blocking biofilm growth;

- Explanation of the real part of the biofilm in C. glabrata in the antifungal resistance process (and the other species of the genus). Characterization of the existent molecules and their function in the therapeutics and the clinical approach;

- Future studies should also focus on C. glabrata biofilms' matrices composition in the presence and absence of antifungal agents and, thus, investigate the use of new alternative therapies to reduce and/or eradicate biofilms.

\section{Conclusion}

Fluctuations in the host are generally required for the opportunistic yeasts to modify from harmless commensal microorganisms to potentially life-threatening human pathogens. The management of candidosis comprises the identification and control of host factors that may predispose one to infection. Candida glabrata displays several virulence factors (adherence, biofilm formation, and secretion of hydrolytic enzymes), swelling their persistence within the host, triggering host cell damage, and, finally, resulting in clinical and microbiological failure. Therefore, the increase in the incidence and antifungal resistance of $C$. glabrata leads to high morbidity and mortality, and make it crucial to further develop our knowledge on the virulence and resistance mechanisms associated with this species. As long as the various classes of antifungals are being used, therapeutic or prophylactically, and sometimes indiscriminately, resistance mechanisms are emerging, and the therapeutic solutions becoming narrower. These mechanisms cover all antifungal classes, but mostly the azoles, which are the most commonly used by physicians, in both ambulatory and hospital environments.

An improved understanding of the pharmacological tolerance phenomena, towards the biochemical mutations and the pharmacokinetics and pharmacodynamics modifications, can contribute actively to the identification of new targets for novel therapeutics against $C$. glabrata.

Acknowledgments The authors are grateful to strategic project PTDC/ SAU-MIC/119069/2010 for the financial support to the research center and for Célia F. Rodrigues' grant.

Conflict of interest The authors declare that they have no conflict of interest.

\section{References}

1. Lass-Flörl C (2009) The changing face of epidemiology of invasive fungal disease in Europe. Mycoses 52:197-205

2. Silva S, Negri M, Henriques M, Oliveira R, Williams DW, Azeredo J (2012) Candida glabrata, Candida parapsilosis and Candida tropicalis: biology, epidemiology, pathogenicity and antifungal resistance. FEMS Microbiol Rev 36(2):288-305. doi:10.1111/j.15746976.2011.00278.x

3. Odds FC (1988) Candida and candidosis, 2nd edn. Bailliere Tindall, London, UK

4. Calderone RA (2002) Introduction and historical perspectives. In: Calderone RA (ed) Candida and candidiasis. ASM Press, Washington D.C., pp 15-25

5. Pfaller MA, Diekema DJ (2007) Epidemiology of invasive candidiasis: a persistent public health problem. Clin Microbiol Rev 20: 133-163

6. Bassetti M, Righi E, Costa A et al (2006) Epidemiological trends in nosocomial candidemia in intensive care. BMC Infect Dis 6:21

7. Colombo AL, Guimarães T, Silva LR et al (2007) Prospective observational study of candidemia in São Paulo, Brazil: incidence rate, epidemiology, and predictors of mortality. Infect Control Hosp Epidemiol 28:570-576

8. Chakrabarti A, Chatterjee SS, Rao KLN et al (2009) Recent experience with fungaemia: change in species distribution and azole resistance. Scand J Infect Dis 41:275-284

9. Hasan F, Xess I, Wang X, Jain N, Fries BC (2009) Biofilm formation in clinical Candida isolates and its association with virulence. Microbes Infect 11:753-761

10. Krcmery V (1999) Torulopsis glabrata: an emerging yeast pathogen in cancer patients. Int J Antimicrob Agents 11:1-6 
11. Krcmery V, Barnes AJ (2002) Non-albicans Candida spp. causing fungaemia: pathogenicity and antifungal resistance. J Hosp Infect 50:243-260

12. Kaur R, Domergue R, Zupancic ML, Cormack BP (2005) A yeast by any other name: Candida glabrata and its interaction with the host. Curr Opin Microbiol 8:378-384

13. Pfaller MA, Diekema DJ (2004) Twelve years of fluconazole in clinical practice: global trends in species distribution and fluconazole susceptibility of bloodstream isolates of Candida. Clin Microbiol Infect 10(Suppl 1):11-23

14. Bethea EK, Carver BJ, Montedonico AE, Reynolds TB (2010) The inositol regulon controls viability in Candida glabrata. Microbiology 156:452-462

15. Sardi JCO, Scorzoni L, Bernardi T, Fusco-Almeida AM, Mendes Giannini MJS (2013) Candida species: current epidemiology, pathogenicity, biofilm formation, natural antifungal products and new therapeutic options. J Med Microbiol 62:10-24

16. Kim J, Sudbery P (2011) Candida albicans, a major human fungal pathogen. J Microbiol 49:171-177

17. Lim CS, Rosli R, Seow HF, Chong PP (2012) Candida and invasive candidiasis: back to basics. Eur J Clin Microbiol Infect Dis 31:21-31

18. Vincent JL, Rello J, Marshall J et al (2009) International study of the prevalence and outcomes of infection in intensive care units. JAMA 302:2323-2329

19. Wisplinghoff H, Seifert H, Wenzel RP, Edmond MB (2006) Inflammatory response and clinical course of adult patients with nosocomial bloodstream infections caused by Candida spp. Clin Microbiol Infect 12:170-177

20. Vazquez JA, Dembry LM, Sanchez V et al (1998) Nosocomial Candida glabrata colonization: an epidemiologic study. J Clin Microbiol 36:421-426

21. Vazquez JA, Sanchez V, Dmuchowski C, Dembry LM, Sobel JD, Zervos MJ (1993) Nosocomial acquisition of Candida albicans: an epidemiologic study. J Infect Dis 168:195-201

22. Reagan DR, Pfaller MA, Hollis RJ, Wenzel RP (1990) Characterization of the sequence of colonization and nosocomial candidemia using DNA fingerprinting and a DNA probe. J Clin Microbiol 28:2733-2738

23. Hagerty JA, Ortiz J, Reich D, Manzarbeitia C (2003) Fungal infections in solid organ transplant patients. Surg Infect (Larchmt) 4: 263-271

24. Kojic EM, Darouiche RO (2004) Candida infections of medical devices. Clin Microbiol Rev 17:255-267

25. Samaranayake LP, Fidel PL, Naglik JR et al (2002) Fungal infections associated with HIV infection. Oral Dis 8:151-160

26. Rajendran R, Robertson DP, Hodge PJ, Lappin DF, Ramage G (2010) Hydrolytic enzyme production is associated with Candida albicans biofilm formation from patients with type 1 diabetes. Mycopathologia 170:229-235

27. Kuhn DM, Ghannoum MA (2004) Candida biofilms: antifungal resistance and emerging therapeutic options. Curr Opin Investig Drugs 5:186-197

28. de Almeida AA, Mesquita CS, Svidzinski TI, de Oliveira KM (2013) Antifungal susceptibility and distribution of Candida spp. isolates from the University Hospital in the municipality of Dourados, State of Mato Grosso do Sul, Brazil. Rev Soc Bras Med Trop 46(3):335-339. doi:10.1590/0037-8682-0074-2012

29. Fidel PL Jr, Vazquez JA, Sobel JD (1999) Candida glabrata: review of epidemiology, pathogenesis, and clinical disease with comparison to C. albicans. Clin Microbiol Rev 12:80-96

30. Dujon B, Sherman D, Fischer G et al (2004) Genome evolution in yeasts. Nature 430:35-44

31. Wolfe KH, Shields DC (1997) Molecular evidence for an ancient duplication of the entire yeast genome. Nature 387:708-713

32. Butler G, Rasmussen MD, Lin MF et al (2009) Evolution of pathogenicity and sexual reproduction in eight Candida genomes. Nature 459:657-662

33. Brunke S, Hube B (2013) Two unlike cousins: Candida albicans and C. glabrata infection strategies. Cell Microbiol 15(5):701-708

34. Silva S, Negri M, Henriques M, Oliveira R, Williams DW, Azeredo $\mathrm{J}$ (2011) Adherence and biofilm formation of non-Candida albicans Candida species. Trends Microbiol 19(5):241-247. doi:10.1016/j. tim.2011.02.003

35. Butler G, Kenny C, Fagan A, Kurischko C, Gaillardin C, Wolfe KH (2004) Evolution of the MAT locus and its Ho endonuclease in yeast species. Proc Natl Acad Sci U S A 101:1632-1637

36. Hittinger CT, Rokas A, Carroll SB (2004) Parallel inactivation of multiple GAL pathway genes and ecological diversification in yeasts. Proc Natl Acad Sci U S A 101:14144-14149

37. Roetzer A, Gabaldón T, Schüller C (2011) From Saccharomyces cerevisiae to Candida glabrata in a few easy steps: important adaptations for an opportunistic pathogen. FEMS Microbiol Lett 314:1-9

38. Kramer A, Schwebke I, Kampf G (2006) How long do nosocomial pathogens persist on inanimate surfaces? A systematic review. BMC Infect Dis 6:130

39. Cox GM, Harrison TS, Mcdade HC et al (2003) Superoxide dismutase influences the virulence of Cryptococcus neoformans by affecting growth within macrophages. Infect Immun 71(1):173-180

40. Nicola AM, Casadevall A, Goldman DL (2008) Fungal killing by mammalian phagocytic cells. Curr Opin Microbiol 11(4):313-317

41. Segal AW (2005) How neutrophils kill microbes. Annu Rev Immunol 23:197-223

42. Nakagawa Y, Kanbe T, Mizuguchi I (2003) Disruption of the human pathogenic yeast Candida albicans catalase gene decreases survival in mouse-model infection and elevates susceptibility to higher temperature and to detergents. Microbiol Immunol 47(6):395-403

43. Roetzer A, Gratz N, Kovarik P, Schüller C (2010) Autophagy supports Candida glabrata survival during phagocytosis. Cell Microbiol 12(2):199-216

44. Saijo T, Miyazaki T, Izumikawa K et al (2010) Skn7p is involved in oxidative stress response and virulence of Candida glabrata. Mycopathologia 169(2):81-90

45. Lee J, Godon C, Lagniel G et al (1999) Yap1 and Skn7 control two specialized oxidative stress response regulons in yeast. J Biol Chem 274(23):16040-16046

46. Gulshan K, Lee SS, Moye-Rowley WS (2011) Differential oxidant tolerance determined by the key transcription factor Yap1 is controlled by levels of the Yap1-binding protein, Ybp1. J Biol Chem 286(39):34071-34081

47. Roetzer A, Klopf E, Gratz N et al (2011) Regulation of Candida glabrata oxidative stress resistance is adapted to host environment. FEBS Lett 585(2):319-327

48. Kaur R, Ma B, Cormack BP (2007) A family of glycosylphosphatidylinositol-linked aspartyl proteases is required for virulence of Candida glabrata. Proc Natl Acad Sci U S A 104(18):7628-7633

49. Lorenz MC, Bender JA, Fink GR (2004) Transcriptional response of Candida albicans upon internalization by macrophages. Eukaryot Cell 3(5):1076-1087

50. Roetzer A, Gregori C, Jennings AM et al (2008) Candida glabrata environmental stress response involves Saccharomyces cerevisiae Msn2/4 orthologous transcription factors. Mol Microbiol 69(3):603620

51. Seider K, Brunke S, Schild L et al (2011) The facultative intracellular pathogen Candida glabrata subverts macrophage cytokine production and phagolysosome maturation. J Immunol 187(6): 3072-3086

52. Klionsky DJ (2004) Cell biology: regulated self-cannibalism. Nature 431(7004):31-32

53. Klionsky DJ (2005) Autophagy. Curr Biol 15(8):R282-R283 
54. Xie Z, Klionsky DJ (2007) Autophagosome formation: core machinery and adaptations. Nat Cell Biol 9(10):1102-1109

55. Verstrepen KJ, Jansen A, Lewitter F, Fink GR (2005) Intragenic tandem repeats generate functional variability. Nat Genet 37(9): 986-990

56. Sundstrom P (2002) Adhesion in Candida spp. Cell Microbiol 4(8): 461-469

57. Ruan SY, Hsueh PR (2009) Invasive candidiasis: an overview from Taiwan. J Formos Med Assoc 108(6):443-451

58. Kraneveld EA, De Soet JJ, Deng DM et al (2011) Identification and differential gene expression of adhesin-like wall proteins in Candida glabrata biofilms. Mycopathologia 172:415-427. doi:10.1007/ s11046-011-9446-2

59. De Groot PW, Kraneveld EA, Yin QY et al (2008) The cell wall of the human pathogen Candida glabrata: differential incorporation of novel adhesin-like wall proteins. Eukaryot Cell 7(11):1951-1964

60. Domergue R, Castaño I, De Las Peñas A et al (2005) Nicotinic acid limitation regulates silencing of Candida adhesins during UTI. Science 308(5723):866-870

61. Castaño I, Pan SJ, Zupancic M, Hennequin C, Dujon B, Cormack BP (2005) Telomere length control and transcriptional regulation of subtelomeric adhesins in Candida glabrata. Mol Microbiol 55(4): $1246-1258$

62. Jandric Z, Schüller C (2011) Stress response in Candida glabrata: pieces of a fragmented picture. Future Microbiol 6(12):1475-1484

63. Silva S, Henriques M, Hayes A, Oliveira R, Azeredo J, Williams DW (2011) Candida glabrata and Candida albicans co-infection of an in vitro oral epithelium. J Oral Pathol Med 40(5):421-427. doi: 10.1111/j.1600-0714.2010.00981

64. Jayatilake JA, Samaranayake YH, Cheung LK, Samaranayake LP (2006) Quantitative evaluation of tissue invasion by wild type, hyphal and SAP mutants of Candida albicans, and non-albicans Candida species in reconstituted human oral epithelium. J Oral Pathol Med 35(8):484-491

65. Tamura NK, Negri MF, Bonassoli LA, Svidzinski TI (2007) Virulence factors for Candida spp recovered from intravascular catheters and hospital workers hands. Rev Soc Bras Med Trop 40: 91-93

66. Silva S, Henriques M, Martins A, Oliveira R, Williams D, Azeredo J (2009) Biofilms of non-Candida albicans Candida species: quantification, structure and matrix composition. Med Mycol 47:681-689

67. Iraqui I, Garcia-Sanchez S, Aubert S et al (2005) The Yak1p kinase controls expression of adhesins and biofilm formation in Candida glabrata in a Sir4p-dependent pathway. Mol Microbiol 55:1259-1271

68. De Las Peñas A, Pan SJ, Castaño I, Alder J, Cregg R, Cormack BP (2003) Virulence-related surface glycoproteins in the yeast pathogen Candida glabrata are encoded in subtelomeric clusters and subject to RAP1- and SIR-dependent transcriptional silencing. Genes Dev 17:2245-2258

69. Cormack BP, Ghori N, Falkow S (1999) An adhesin of the yeast pathogen Candida glabrata mediating adherence to human epithelial cells. Science 285:578-582

70. Silva S, Henriques M, Oliveira R, Williams D, Azeredo J (2010) In vitro biofilm activity of non-Candida albicans Candida species. Curr Microbiol 61:534-540. doi:10.1007/s00284-010-9649-7

71. van Dyk D, Pretorius IS, Bauer FF (2005) Mss11p is a central element of the regulatory network that controls FLO11 expression and invasive growth in Saccharomyces cerevisiae. Genetics 169: 91-106

72. Riera M, Mogensen E, d'Enfert C, Janbon G (2012) New regulators of biofilm development in Candida glabrata. Res Microbiol 163: 297-307

73. Guo B, Styles CA, Feng Q, Fink GR (2000) A Saccharomyces gene family involved in invasive growth, cell-cell adhesion, and mating. Proc Natl Acad Sci U S A 97:12158-12163
74. Sheppard DC, Yeaman MR, Welch WH et al (2004) Functional and structural diversity in the Als protein family of Candida albicans. J Biol Chem 279:30480-30489

75. Caudle KE, Barker KS, Wiederhold NP, Xu L, Homayouni R, Rogers PD (2011) Genomewide expression profile analysis of the Candida glabrata Pdr1 regulon. Eukaryot Cell 10(3):373-383. doi: 10.1128/EC.00073-10

76. Gutiérrez-Escribano P, Zeidler U, Suárez MB et al (2012) The NDR/ LATS kinase Cbk1 controls the activity of the transcriptional regulator Bcr1 during biofilm formation in Candida albicans. PLoS Pathog 8(5):e1002683. doi:10.1371/journal.ppat.1002683

77. Chakrabarti A, Nayak N, Talwar P (1991) In vitro proteinase production by Candida species. Mycopathologia 114:163-168

78. Marcos-Arias C, Eraso E, Madariaga L, Aguirre JM, Quindós G (2011) Phospholipase and proteinase activities of Candida isolates from denture wearers. Mycoses 54(4):e10-e16. doi:10.1111/j.14390507.2009.01812.x

79. Mohan das V, Ballal M (2008) Proteinase and phospholipase activity as virulence factors in Candida species isolated from blood. Rev Iberoam Micol 25(4):208-210

80. Kalkanci A, Güzel AB, Khalil II, Aydin M, Ilkit M, Kuștimur S (2012) Yeast vaginitis during pregnancy: susceptibility testing of 13 antifungal drugs and boric acid and the detection of four virulence factors. Med Mycol 50(6):585-593. doi:10.3109/13693786.2012. 662597

81. Ueno K, Matsumoto Y, Uno J et al (2011) Intestinal resident yeast Candida glabrata requires Cyb2p-mediated lactate assimilation to adapt in mouse intestine. PLoS One 6(9):e24759

82. Sikora M, Dabkowska M, Swoboda-Kopec E et al (2011) Differences in proteolytic activity and gene profiles of fungal strains isolated from the total parenteral nutrition patients. Folia Microbiol (Praha) 56(2):143-148. doi:10.1007/s12223-011-0023-3

83. Negri M, Martins M, Henriques M et al (2010) Examination of potential virulence factors of Candida tropicalis clinical isolates from hospitalized patients. Mycophatologia 169:175-182. doi:10. 1007/s11046-009-9246-0

84. Luo G, Samaranayake LP (2002) Candida glabrata, an emerging fungal pathogen, exhibits superior relative cell surface hydrophobicity and adhesion to denture acrylic surfaces compared with Candida albicans. APMIS 110:601-610

85. Luo G, Samaranayake LP, Cheung BP, Tang G (2004) Reverse transcriptase polymerase chain reaction (RT-PCR) detection of HLP gene expression in Candida glabrata and its possible role in in vitro haemolysin production. APMIS 112:283-290

86. Berila N, Hyroššová P, Subík J (2011) Oxidative stress response and virulence factors in Candida glabrata clinical isolates. Folia Microbiol (Praha) 56(2):116-121. doi:10.1007/s12223-011-0016-2

87. Bader O, Schwarz A, Kraneveld EA et al (2012) Gross karyotypic and phenotypic alterations among different progenies of the Candida glabrata CBS138/ATCC2001 reference strain. PLoS One 7(12):e52218. doi:10.1371/journal.pone.0052218

88. Rai MN, Balusu S, Gorityala N, Dandu L, Kaur R (2012) Functional genomic analysis of Candida glabrata-macrophage interaction: role of chromatin remodeling in virulence. PLoS Pathog 8(8):e1002863. doi:10.1371/journal.ppat. 1002863

89. Niimi M, Firth NA, Cannon RD (2010) Antifungal drug resistance of oral fungi. Odontology 98(1):15-25

90. Akins RA (2005) An update on antifungal targets and mechanisms of resistance in Candida albicans. Med Mycol 43(4):285-318

91. Van Bambeke F, Balzi E, Tulkens PM (2000) Antibiotic efflux pumps. Biochem Pharmacol 60(4):457-470

92. Wilson D, Thewes S, Zakikhany K et al (2009) Identifying infection-associated genes of Candida albicans in the postgenomic era. FEMS Yeast Res 9:688-700

93. Brunke S, Seider K, Almeida RS et al (2010) Candida glabrata 
tryptophan-based pigment production via the Ehrlich pathway. Mol Microbiol 76:25-47

94. Tscherner M, Schwarzmüller T, Kuchler K (2011) Pathogenesis and antifungal drug resistance of the human fungal pathogen Candida glabrata. Pharmaceuticals 4:169-186. doi:10.3390/ph4010169

95. Henry KW, Nickels JT, Edlind TD (2000) Upregulation of ERG genes in Candida species by azoles and other sterol biosynthesis inhibitors. Antimicrob Agents Chemother 44(10):2693-2700

96. Stead DA, Walker J, Holcombe L et al (2009) Impact of the transcriptional regulator, Ace2, on the Candida glabrata secretome. Proteomics 10:212-223

97. Calcagno AM, Bignell E, Warn P et al (2003) Candida glabrata STE12 is required for wild-type levels of virulence and nitrogen starvation induced filamentation. Mol Microbiol 50:1309-1318

98. Ferrari S, Sanguinetti M, De Bernardis F et al (2011) Loss of mitochondrial functions associated with azole resistance in Candida glabrata results in enhanced virulence in mice. Antimicrob Agents Chemother 55:1852-1860

99. Kaur R, Castaño I, Cormack BP (2004) Functional genomic analysis of fluconazole susceptibility in the pathogenic yeast Candida glabrata: roles of calcium signaling and mitochondria. Antimicrob Agents Chemother 48:1600-1613

100. Miyazaki T, Yamauchi S, Inamine T et al (2010) Roles of calcineurin and crz1 in antifungal susceptibility and virulence of Candida glabrata. Antimicrob Agents Chemother 54:1639-1643

101. Bennett JE, Izumikawa K, Marr KA (2004) Mechanism of increased fluconazole resistance in Candida glabrata during prophylaxis. Antimicrob Agents Chemother 48:1773-1777

102. Noble JA, Tsai HF, Suffis SD, Su Q, Myers TG, Bennett JE (2013) STB5 Is a negative regulator of azole resistance in Candida glabrata. Antimicrob Agents Chemother 57(2):959-967. doi:10.1128/AAC. 01278-12

103. Vermitsky JP, Edlind TD (2004) Azole resistance in Candida glabrata: coordinate upregulation of multidrug transporters and evidence for a Pdr1-Like transcription factor. Antimicrob Agents Chemother 48:3773-3781

104. Vale-Silva L, Ischer F, LeibundGut-Landmann S, Sanglard D (2013) Gain-of-function mutations in PDR1, a regulator of antifungal drug resistance in Candida glabrata, control adherence to host cells. Infect Immun 81(5):1709-1720. doi:10.1128/IAI.00074-13

105. Paul S, Schmidt JA, Moye-Rowley WS (2011) Regulation of the CgPdr1 transcription factor from the pathogen Candida glabrata. Eukaryot Cell 10(2):187-197

106. Ferrari S, Sanguinetti M, Torelli R, Posteraro B, Sanglard D (2011) Contribution of CgPDR1-regulated genes in enhanced virulence of azole-resistant Candida glabrata. PLoS One 6(3):e17589. doi:10. 1371/journal.pone.0017589

107. Chen KH, Miyazaki T, Tsai HF, Bennett JE (2007) The bZip transcription factor Cgap $1 \mathrm{p}$ is involved in multidrug resistance and required for activation of multidrug transporter gene CgFLR1 in Candida glabrata. Gene 386(1-2):63-72

108. Farahyar S, Zaini F, Kordbacheh P et al (2013) Overexpression of aldo-keto-reductase in azole-resistant clinical isolates of Candida glabrata determined by cDNA-AFLP. Daru 21:1

109. Thompson GR 3rd, Wiederhold NP, Vallor AC, Villareal NC, Lewis JS 2nd, Patterson TF (2008) Development of caspofungin resistance following prolonged therapy for invasive candidiasis secondary to Candida glabrata infection. Antimicrob Agents Chemother 52: 3783-3785

110. Pfaller MA, Castanheira M, Lockhart SR, Ahlquist AM, Messer SA, Jones RN (2012) Frequency of decreased susceptibility and resistance to echinocandins among fluconazole-resistant bloodstream isolates of Candida glabrata. J Clin Microbiol 50:1199-1203

111. Arendrup MC, Perlin DS, Jensen RH, Howard SJ, Goodwin J, Hope W (2012) Differential in vivo activities of anidulafungin, caspofungin, and micafungin against Candida glabrata isolates with and without FKS resistance mutations. Antimicrob Agents Chemother 56:2435-2442

112. Shields RK, Nguyen MH, Press EG et al (2012) The presence of an FKS mutation rather than MIC is an independent risk factor for failure of echinocandin therapy among patients with invasive candidiasis due to Candida glabrata. Antimicrob Agents Chemother 56: $4862-4869$

113. Alexander BD, Johnson MD, Pfeiffer CD et al (2013) Increasing echinocandin resistance in Candida glabrata: clinical failure correlates with presence of FKS mutations and elevated minimum inhibitory concentrations. Clin Infect Dis 56(12):1724-1732

114. Vandeputte P, Tronchin G, Larcher G et al (2008) A nonsense mutation in the ERG6 gene leads to reduced susceptibility to polyenes in a clinical isolate of Candida glabrata. Antimicrob Agents Chemother 52:3701-3709

115. Vandeputte P, Tronchin G, Bergès T, Hennequin C, Chabasse D, Bouchara JP (2007) Reduced susceptibility to polyenes associated with a missense mutation in the erg6 gene in a clinical isolate of Candida glabrata with pseudohyphal growth. Antimicrob Agents Chemother 51:982-990

116. Helmerhorst EJ, Venuleo C, Sanglard D, Oppenheim FG (2006) Roles of cellular respiration, $\mathrm{CgCDR} 1$, and $\mathrm{CgCDR} 2$ in Candida glabrata resistance to histatin 5. Antimicrob Agents Chemother 50: $1100-1103$

117. Edgerton M, Koshlukova SE (2000) Salivary histatin 5 and its similarities to the other antimicrobial proteins in human saliva. Adv Dent Res 14:16-21

118. Helmerhorst EJ, Oppenheim FG (2004) The antifungal mechanisms of antimicrobial proteins. In: Hancock REW, Devine D (eds) Mammalian antimicrobial proteins, 1st edn. Cambridge University Press, Cambridge, pp 245-277

119. Oppenheim FG (1989) Salivary histidine-rich proteins. In: Tenovuo JO (ed) Human saliva: clinical chemistry and microbiology. CRC Press, Boca Raton, pp 151-160

120. Oppenheim FG, Xu T, McMillian FM et al (1988) Histatins, a novel family of histidine-rich proteins in human parotid secretion. Isolation, characterization, primary structure, and fungistatic effects on Candida albicans. J Biol Chem 263:7472-7477

121. Tsai H, Bobek LA (1998) Human salivary histatins: promising antifungal therapeutic agents. Crit Rev Oral Biol Med 9:480-497

122. Van Urk H, Voll WSL, Scheffers WA, van Dijken JP (1990) Transient-state analysis of metabolic fluxes in Crabtree-positive and Crabtree-negative yeasts. Appl Environ Microbiol 56:281-287

123. Niimi M, Kamiyama A, Tokunaga M (1988) Respiration of medically important Candida species and Saccharomyces cerevisiae in relation to glucose effect. J Med Vet Mycol 26:195-198

124. Shahi P, Moye-Rowley WS (2009) Coordinate control of lipid composition and drug transport activities is required for normal multidrug resistance in fungi. Biochim Biophys Acta 1794:852-859

125. Muller H, Thierry A, Coppée JY et al (2009) Genomic polymorphism in the population of Candida glabrata: Gene copy-number variation and chromosomal translocations. Fungal Genet Biol 46: 264-276

126. Thierry A, Bouchier C, Dujon B, Richard GF (2008) Megasatellites: a peculiar class of giant minisatellites in genes involved in cell adhesion and pathogenicity in Candida glabrata. Nucleic Acids Res 36(18):5970-5982

127. Barchiesi F, Falconi Di Francesco L, Arzeni D, Caselli F, Gallo D, Scalise G (1999) Electrophoretic karyotyping and triazole susceptibility of Candida glabrata clinical isolates. Eur J Clin Microbiol Infect Dis 18:184-187

128. Kaufmann CS, Merz WG (1989) Electrophoretic karyotypes of Torulopsis glabrata. J Clin Microbiol 27:2165-2168

129. Klempp-Selb B, Rimek D, Kappe R (2000) Karyotyping of Candida albicans and Candida glabrata from patients with Candida sepsis. Mycoses 43:159-163 
130. Lin CY, Chen YC, Lo HJ, Chen KW, Li SY (2007) Assessment of Candida glabrata strain relatedness by pulsed-field gel electrophoresis and multilocus sequence typing. J Clin Microbiol 45:2452-2459

131. Shin JH, Chae MJ, Song JW et al (2007) Changes in karyotype and azole susceptibility of sequential bloodstream isolates from patients with Candida glabrata candidemia. J Clin Microbiol 45:2385-2391

132. Magee BB, Sanchez MD, Saunders D, Harris D, Berriman M, Magee PT (2008) Extensive chromosome rearrangements distinguish the karyotype of the hypovirulent species Candida dubliniensis from the virulent Candida albicans. Fungal Genet Biol 45:338-350

133. Samaranayake LP (1990) Host factors and oral candidosis. In: Samaranayake LP, MacFarlane TW (eds) Oral candidosis. WrightButterworth, London, pp 66-103

134. Hawser SP, Baillie GS, Douglas LJ (1998) Production of extracellular matrix by Candida albicans biofilms. J Med Microbiol 47(3): 253-256

135. Chandra J, Mukherjee PK, Leidich SD et al (2001) Antifungal resistance of candidal biofilms formed on denture acrylic in vitro. J Dent Res 80(3):903-908

136. Al-Fattani MA, Douglas LJ (2004) Penetration of Candida biofilms by antifungal agents. Antimicrob Agents Chemother 48(9): 3291-3297

137. Blankenship JR, Mitchell AP (2006) How to build a biofilm: a fungal perspective. Curr Opin Microbiol 9(6):588-594

138. Chandra J, Kuhn DM, Mukherjee PK, Hoyer LL, McCormick T, Ghannoum MA (2001) Biofilm formation by the fungal pathogen Candida albicans: development, architecture, and drug resistance. J Bacteriol 183(18):5385-5394

139. Ramage G, Vande Walle K, Wickes BL, López-Ribot JL (2001) Standardized method for in vitro antifungal susceptibility testing of Candida albicans biofilms. Antimicrob Agents Chemother 45(9): 2475-2479

140. Hawser S (1996) Adhesion of different Candida spp. to plastic: XTT formazan determinations. J Med Vet Mycol 34(6):407-410

141. Mah TFC, O'Toole GA (2001) Mechanisms of biofilm resistance to antimicrobial agents. Trends Microbiol 9:34-39
142. Uppuluri P, Chaturvedi AK, Srinivasan A et al (2010) Dispersion as an important step in the Candida albicans biofilm developmental cycle. PLoS Pathog 6(3):e1000828

143. Perumal P, Mekala S, Chaffin WL (2007) Role for cell density in antifungal drug resistance in Candida albicans biofilms. Antimicrob Agents Chemother 51(7):2454-2463

144. Ramage G, Rajendran R, Sherry L, Williams C (2012) Fungal biofilm resistance. Int J Microbiol 2012:528521. doi:10.1155/ 2012/528521

145. Bandara HM, Lam OL, Watt RM, Jin LJ, Samaranayake LP (2010) Bacterial lipopolysaccharides variably modulate in vitro biofilm formation of Candida species. J Med Microbiol 59(Pt 10):12251234. doi:10.1099/jmm.0.021832-0

146. Halliwell SC, Smith MCA, Muston P, Holland SL, Avery SV (2012) Heterogeneous expression of the virulence-related adhesin Epa1 between individual cells and strains of the pathogen Candida glabrata. Eukaryot Cell 11(2):141-150

147. Taff HT, Nett JE, Zarnowski R et al (2012) A Candida biofilm-induced pathway for matrix glucan delivery: implications for drug resistance. PLoS Pathog 8(8):e1002848. doi: 10.1371/journal.ppat. 1002848

148. Cannon RD, Lamping E, Holmes AR et al (2007) Candida albicans drug resistance - another way to cope with stress. Microbiology 153(Pt 10):3211-3217

149. Seneviratne CJ, Wang Y, Jin L, Abiko Y, Samaranayake LP (2010) Proteomics of drug resistance in Candida glabrata biofilms. Proteomics 10:1444-1454

150. LaFleur MD, Kumamoto CA, Lewis K (2006) Candida albicans biofilms produce antifungal-tolerant persister cells. Antimicrob Agents Chemother 50(11):3839-3846

151. Lewis K (2008) Multidrug tolerance of biofilms and persister cells. Curr Top Microbiol Immunol 322:107-131

152. Lewis K (2010) Persister cells. Annu Rev Microbiol 64:357-372

153. Lafleur MD, Qi Q, Lewis K (2010) Patients with long-term oral carriage harbor high-persister mutants of Candida albicans". Antimicrob Agents Chemother 54(1):39-44 